\title{
Relationship Strategy Family Coping With Quality Of Life In Elderly Post Stroke
}

\author{
Dodik Limansyah, Junaiti Sahar, Sukihananto ${ }^{1}$ \\ ${ }^{I}$ STIKes Yarsi Pontianak, Kalimantan Barat, Indonesia \\ Corresponding author : dodik.limansyah@yahoo.com
}

\begin{abstract}
Background: Stroke is the highest cause of death in urban areas, one of the regions in Indonesia with stroke exceeds the national rate is the city of Pontianak.

Purpose : This study aims to determine the relationship of family coping strategies to the quality of life of elderly post-stroke in the city of Pontianak.

Methods : Analytical research design correlation with cross sectional approach. sampling in total sampling with respondents amounted to 58 respondents. The sample of this study was post-stroke elderly and family members as caregiver or primary outpatient who treated elderly with post stroke.

Result : The results of multiple linear regression analysis or anova test ( $\mathrm{f}$ test) with $\mathrm{p}$ value $=0.001(<0.05)$ indicating that there is a significant relationship between social support, reframing, seeking and receiving, passive income and income with the quality of life of the elderly post stroke.

Conclusion : Social support is a dominant element of coping strategy. The role of community nurses is needed to support family caregivers in providing social support to post-stroke elderly.
\end{abstract}

Keywords : Coping strategies, Stroke, WHOQOL-Bref

How to Cite: Limansyah, D., Sahar, J., Sukihananto, S. (2018). Relationship Strategy Family Coping With Quality Of Life In Elderly Post Stroke. Journal Of Nursing Practice, 2(1), 7-16.

https://doi.org/10.30994/jnp.v2i1.37 


\section{BACKGROUND}

Vulnerability is a weakness to health problems (Shi \& Steven, 2010, Allender, 2014). Vulnerable populations are in a group of adverse health risks, susceptibility is associated with an increased risk of morbidity and mortality. Vulnerable characteristics are characteristic of populations at risk of declining health status both physically, psychologically and socioeconomically (AJMC, 2006).

Stroke is one of the diseases suffered by many elderly, currently stroke is one of the many diseases found mainly at the age of 45 years and over (Riskesdas, 2007). Elderly with a stroke in rehabilitation or continuing care at home or community is highly dependent on family members, the family as a cargiver should have both physical and emotional resilience in carrying out rehabilitation. Chaiyawat (2012) stated the initial effectiveness of home rehabilitation programs during the first 6 months post stroke period leads to improvements and functions that will reduce disability and improve quality of life.

The prevalence of national stroke is $0.8 \%$ of the total population of Indonesia. This figure has not been seen from other variables such as regional type, if seen from the spread based on the type of regional prevalence of stroke nationally in urban areas is $0.9 \%$ and in rural $0.78 \%$ of the total population. One area in Indonesia with stroke exceeds the national rate of Pontianak with a prevalence of $1.4 \%$. This prevalence exceeds the National prevalence rate of $0.8 \%$. (Ministry of Health, 2007).

The task of treating patients Stroke in a long time will increase the burden experienced by caregiver family. This condition is exacerbated by a lack of caregiver knowledge in treating patients at home. The burden experienced by caregivers occurs due to several reasons such as feeling the task of caring for patients as a difficult task, unclear about the treatment of stroke patients, barriers in social relations during caring for patients and the feeling that patients should be helped maximally in self-care. Caregiver plays an important role in post-stroke rehabilitation of patients especially when undergoing rehabilitation at home. Darlington et al, (2007) in his research says that coping is a very powerful factor that affects the quality of life (QOL) of post-stroke patients. Given the importance of caregiver coping in post-stroke rehabilitation, the patient's output is strongly influenced by caregiver coping strategies.

Coping Family (F-Cope) strategy according to McCubbin (1991) in Friedman (2010) is divided internally and externally, internal coping such as family coping pattern, family resource derived from family resources consisting of confidence in problem solving (confidence in problem solving), arranging family problems (reframing family problems), and family passivity or inactive or passive family behavior. Koping consists of problemsolving efforts faced by individuals with demands that are highly relevant to well-being, but burdensome to one's source (Lazarus, Averill, \& Opton, 1974) in Friedman (2010). The gap between several facts about stroke such as increased prevalence of cases, the biggest cause of death, inadequate rehabilitation of in-house patients where this is influenced by coping and family coping strategies as caregivers who provide home care. For that family as caregiver need to maintain koping and family coping strategies to improve the quality of life of elderly, especially elderly with post stroke.

\section{OBJECTIVE}

This study aims to determine the relationship of family coping strategies to the quality of life of elderly post-stroke in the city of Pontianak. 


\section{METHODS}

The design of this research is descriptive correlation with cross sectional approach method (point time approach). The measurement of this study measures the variables of family coping strategies including social support, reframing, searching and receiving efforts, passive acceptance and income confounding variables with the quality of life of elderly post-stroke patients at the same time.

The population in this study were all post-stroke elderly people aged 60 years or older and family cargiver as main offender who live in Pontianak city area. Sample in this research is all elderly stroke post-care hospital that aged 60 years or more residing in Pontianak city area, the amount of sample in this research as much 58 responder. Sampling method used in this research is total sampling technique, that is sample determination technique by taking all member of population as respondent or sample.

\section{RESULTS}

Table 1

The relationship between family coping strategies and the quality of life (QOL) of poststroke elderly people in Pontianak $(n=58)$

\begin{tabular}{llcc}
\hline \multicolumn{1}{c}{ Independent Variable } & Dependent Variable & r Value & $\begin{array}{c}\boldsymbol{P} \\
\text { value }\end{array}$ \\
\hline Family coping strategy & Quality of Life & 0,293 & 0,026 \\
\hline Social support & Quality of Life & 0,376 & 0,004 \\
\hline Reframing & Quality of Life & 0,252 & 0,056 \\
\hline Spiritual support & Quality of Life & $-0,300$ & 0,022 \\
\hline $\begin{array}{l}\text { Family businesses seek and receive } \\
\text { help }\end{array}$ & Quality of Life & 0,165 & 0,216 \\
\hline Passive appraiasal & Quality of Life & $-0,217$ & 0,102 \\
\hline
\end{tabular}

Pearson correlation test result ( $p$ value $\leq 0,05$ ) which indicate that family coping strategy significantly correlated with quality of life of elderly post-stroke.

The analysis of correlation between social support variable with quality of life of elderly post stroke with Pearson correlation test resulted in probability value 0,004 ( $\mathrm{p}$ value $\leq 0,05$ ) indicating that family social support significantly correlated with quality of life of elderly post stroke.

Analysis of the relationship between reframing variables and the quality of life of elderly post-stroke. The Pearson correlation test yielded a probability value of $0.056(p$ value $\geq 0.05$ ) indicating that reframing did not significantly correlate with post-stroke survival elderly.

The analysis of the relationship between the variables of family effort seeking and receiving help shows that spiritual support is not significantly related to the quality of life of elderly post-stroke, while passive acceptance is not significantly associated with poststroke survival of elderly. 
Table 2

Late Linear Regression Model Double relationship of family coping strategy with poststroke life quality of elderly in Pontianak $(n=58)$

\begin{tabular}{llccc}
\hline No & \multicolumn{1}{c}{ Model } & Koefisien B & p value & $\begin{array}{c}\boldsymbol{R} \text { square } \\
\left(\mathbf{R}^{\mathbf{2}} \mathbf{r}\right.\end{array}$ \\
\hline 1. & Constants & 13,199 & 0,549 & \\
2. & Social support & 1,013 & 0,001 & 0,312 \\
3. & Reframing & 0,507 & 0,14 & \\
4. & Efforts to find and receive & 0,827 & 0,121 & \\
5. & Passive acceptance & 0,258 & 0,481 & \\
6. & Family income & $-1.6 \mathrm{E}, 006$ & 0,088 & \\
\hline
\end{tabular}

The final model shows that the independent variables that enter the linear regression model are social support, reframing, effort seeking and receiving passive help and acceptance as well as the confounding variable that is family income. R Square value shows the value of 0.312 means that the regression model obtained can explain $31.2 \%$ variation of the dependent variable quality of life of the elderly. In the table ANOVA F test results show that the value of $p=0.001$ means at alpha $5 \%$ can state that the regression model fit (fit) with existing data. Dependent and independent variables can be used to predict the elderly's quality of life variables. Based on the value of coefficient B in table 2 it can be determined multiple linear regression model as follows:

$\mathrm{Y}=13,199+1,013 \mathrm{X}_{1}+0,507 \mathrm{X}_{2}+0,827 \mathrm{X}_{3}+0,258 \mathrm{X}_{4}-0,0000016 \mathrm{X}_{5}$
Kualitas Hidup Lansia $=13,199+1,013$ Dukungan Sosial + 0,507 Reframing + 0,827 Usaha mencari dan menerima pertolongan $+0,258$ Penerimaan pasif-0,0000016 Pendapatan keluarga.

The most influential variable in this research is social support variable, because the value of $p=0.001$ with the largest value of $B$ coefficient is 1.013 , where every increase of 1 score of social support value, then the elderly quality of life value will increase by 1.013 where the relationship of social support variable with the quality of life together with other variables produce the number 1,013 ie, reframing variables, effort seeking and receiving help, passive acceptance and family income

\section{DISCUSSION}

Results Analysis on quality of life of post-stroke elderly in Pontianak city showed that mean of quality of life of post-stroke elderly in town of Pontianak is equal to 76,29 (SD 5,651), result of mean interval estimate of quality of life quality of post-stroke elderly in population Pontianak is between 74.81 to 77.78. The WHOQOL-BREF questionnaire is divided into 4 domains: physical domain, psychology, social relations, and environment. Conversion results from 4 domain average quality of life of elderly post stroke for physical domain 46,41 (SD 9,19). 
The mean comparison of quality of life of Chiu et al (2006) study conducted in Taiwan using WHOQOL-BREF instrument in acute stroke patients with $\mathrm{n}=199$ mean age $=72$ average physical health 15.1 (SD 2.7), psychology 13, 9 (SD 2.5), average of social relationship 14,2 (SD 19,6), and environment 13,7 (SD 2,1). This shows that the average quality of life of post-stroke elderly people in Pontianak is still above the average quality of life of acute stroke population in Taiwan. Based on the analysis of the researchers, this difference may be due to the age of respondents in Taiwan average 72 years and this research is done in acute stroke, and ethnicity or social culture factor also can influence health status where pontianak city consists of various tribes and culture. Ethnic factors play an important role in the maintenance of family health (Stuart and Laraia, 2005).

Edwards and O'connell's study (2003) was performed on chronic stroke in Australia using WHOQOL-BREF instrument with $\mathrm{n}=74$ mean age $=58.35$ average physical health 60.5 (SD 21.2), psychology 59.8 (SD 21,5), average social relation 62.1 (SD 25,4), and environment 67,9 (SD 19,1). This shows that the average quality of stroke chronicles higher than the average post-stroke elderly in the city of Pontianak. This difference is due to the research of o'connel performed on chronic strokes and performed in developed countries so that resources and care facilities for stroke patients are different, and in general post-chronic stroke has been dating and have a more effective coping.

Differences between caregiver caring for post-stroke patients between 1 month and 6 months where coping ability (cargiver coping ability) over 6 months is more effective which can affect quality of life (Puymbroeck, 2005). Chaiyawat (2012) stated the initial effectiveness of home rehabilitation programs during the first 6 months post stroke period leads to improvements and functions that will reduce disability and improve quality of life.

This quality of life evaluation instrument has been applied internationally and crossculturally and has tested its validity and reliability. Jennifer et.al (2009) in her study stated that the strongest predictors of stroke patients were their initial perception of HRQOL and the effect of caregiver depression during post-stroke rehabilitation that may affect the quality of life in stroke patients. Sutikno (2011) states that quality elderly life is functional condition of elderly at optimal condition, so that they can enjoy their old age with full meaning, happy and useful.

The family relationship with the highest elderly was $79.3 \%$ for children, this was in agreement with his research $\mathrm{Wu}$, et al, (2009) which stated that after post hospitalization $85-90 \%$ of stroke patients treated by family members at home, including about $10-15 \%$ treated by nurses who work at home. The family continues to take responsibility for stroke patients. Kaakinen et al. (2010) in Allender (2014) also defines families as two or more individuals dependent on one another in emotional, physical, and economic support. His research, Saban and Hogan (2012), which states that cargivers who have a family relationship and female sex are more caring for their loved stroke patients and more quickly adapt to changes that occur and further improve the effectiveness in providing treatment for stroke patients.

Confounding income variable when tested model in multivariate, giving influence to other independent variable more than $10 \%$. From the meaning of the coefficient beta states that Any increase of 1 rupiah in family income, then the elderly quality of life will decrease by 0,0000016 after controlled social support, reframing, searching and receiving passive help and acceptance. 
The results are inversely proportional to the theory that income or economic factors affect quality of life. Parker (2012) states that resources in this regard are the costs required for checks during rehabilitation to improve the quality of life of clients post-stroke. (Flores \& Tomany-Korman, 2008; Hausmann, Jeong, Bost, \& Ibrahim, 2008; Allender, 2014) access of the poor to health services becomes a gap to obtain quality services.

(Stuart and Laraia, 2005) argue that economic factors are a crucial risk in seeking help in using in-house facilities, with low socioeconomic families experiencing difficulties in using health facilities such as money, goods or services that can be purchased. The higher the available resources, the family coping strategy will be stronger.Francisco (2009) states that physical and psychosocial well-being is influenced by their clients and caregivers.

Based on the analysis researchers can be assumed that the relationship of blood or family has a high emotional relationship and have a commitment between caregiver with elderly post stroke so it will cause a great sense of responsibility. Revenue in theory greatly affects the health status where clients can access health facilities.

The result of bivariate test shows that family coping strategy in Pontianak is significantly related to the quality of life of elderly post stroke. Family coping strategies are divided into 5 subvariables (ie McCubbin, Olson \& Larsen, 1991; Walsh, 2998; Friedman 2010); social support, reframing, spiritual support, seeking and receiving help, and passive acceptance. Coping strategies are done effectively stressor no longer cause pressure psychologically, or physically but will be a stimulant that spurs achievement and physical and mental condition better.

Based on respondents' answers that most respondents are trying to try to solve the problem as soon as possible. Darlington (2007) in his research stated that coping strategy is the most important determinant affecting quality of life, and he also states that coping has a big effect after 5 months of discharge.

Social support resulted in a $\mathrm{p}$ value of 0.004 from bivariate test results indicating that soial support has a very significant relationship with the quality of life of elderly poststroke. The end result of the multiple linear regression model states that every increase of 1 score of social support value then the quality of life number will increase 1.013 which means that the relationship of social support variable with quality of life together with reframing variables of effort seeking and receiving help, passive acceptance and family income .

Research conducted by Grant (2007) which states that social support and emotional focus is a component that contributes to cargiver self-adjustment in problem solving.

Families utilizing social support systems in family social networks are a very important external family coping strategy that functions as a social, psychological, and behavioral function. Dayapoglu (2010) also stated that Quality of life score has positive impact and has significant relation with social support from family scale and aspect of life quality variable such as functional status, welfare, perception to general health and general life quality.

Liu (2005) in his research stated that social support including family support is an effective factor in solving problems with chronic diseases that can improve health status in improving quality of life. This is supported by respondents' answers mostly answered that they shared difficulties with their immediate family, asked for advice, discussed problems with their neighbors and asked the close family about how they felt about the problem, so that the elderly received massive social support from the family that could improve quality of life. 
The reframing variable with quality yielded a value ( $\mathrm{p}$ value $>0.05$ ) indicating that reframing did not significantly correlate with post-stroke survival of the elderly (Clarke et al, 2010) in his research suggesting that short-runs to risk managment have implications for well being ( welfare) of individuals and is recommended for comprehensive assessment so that they know what they need.

Reframing is especially necessary in times of cryicitis or in acute stroke, which will improve the effectiveness of solving health problems especially in post-stroke elderly people who are attacked between 3-6 months. If this can be done then the quality of life of elderly post-stroke will increase. This is supported by the responses of respondents who mostly stated that they have the strength or ability to solve the problem.

Results Analysis of spiritual support with quality of life in the city of Pontianak ( $p$ value $<0.05$ ) indicates that spiritual support is significantly related to the quality of life of elderly post-stroke. Spiritual trust is the individual and family religion is the core of all koping and family adaptation. Confidence is a major force in increasing family resilience in family coping strategies (McCubbin, Olson \& Larsen, 1991; Walsh, 2998; Friedman 2010).

Based on the above results, the spiritual support provided by the family in this case caregiver will increase the sense of comfort and safe in the elderly post stroke especially in the acute phase, because it will improve the psychosocial well being which will ultimately improve the quality of life of elderly post-stroke. This is supported by respondents' answers, most of whom claimed they were following religious activities in the mosque / church, asking for advice from religious leaders and believing in God's greatness.

Based on the calculation in modeling the change of coefficient value B on each independent variable of effort seek and receive help turns out there is value that change more than $10 \%$, that is equal to $(25,41 \%)$, it can be concluded that business variable seek and accept has a meaningful relationship with the quality of life. From the results of coefficient $B$ on this variable states that every 1 digit increase in business variables seek and receive help then the quality of life will rise by 0.827

\section{CONCLUSION}

Based on the results of research on the relationship of family coping strategies to the quality of life of post-stroke elderly in the city of Pontianak, obtained the following conclusions:

1. Characteristics of post-stroke elderly in the city of Pontianak on average 65 years old, stroke less than 6 months, most categories of male sex, and low-educated. The characteristics of the families caring for the post-stroke elderly in Pontainak are mostly female and have a family relationship as and the mean age after 33 years

2. Quality of life post-stroke elderly in the city of Pontianak an average of 76.29. Conversion results from 4 domains mean the elderly's quality of life for social relations domains had the highest mean value.

3. Family coping strategies have a significant relationship with the quality of life of elderly post stroke in general in the city of Pontianak.

4. Social support given is to tell the family difficulty with close family, friends or neighbors.

5. Reframing given to elderly post-stroke families is that they have the ability to solve problems, the family has the power to solve problems, and show others that the family is strong and steadfast in the face of problems. 
6. Spiritual support is given to follow the study activity in the mosque or other places of worship, participate in religious activities, seek advice from religious leaders, and believe in the greatness of God.

7. Attempt to seek and receive help given to seek advice from other families who have similar problems, ask for help from puskesmas, ask for explanations and advice from doctors, ask for help and consult the experts.

8. Family income in the city of Pontianak is the only confounding variable that affects independent and dependent variables.

\section{REFERENCES}

Adientya, G \& Handayani, F.(2012). Stres pada kejadian stroke. Jurnal Nursing Studies. Vol. 1. Hal $183-188$.

Anonim (2014). Vulbarable population; Who Are They. Website: http://www.ajmc.com/publications/diunduh tanggal 20 Februari 2014

Anonim (2014). health Policy Vulbarable population. Website: http://www.urban.org/health_policy/vulnerable_populations index.cfm. diunduh tanggal 23 Februari 2014.

Anderson, E. T., \& McFarlane, J. M. (2011). Community as partner : theory and practice in nursing. Philadelphia: Wolters Kluwer Health/Lippincott Williams \& Wilkins.

Allender, J. A., Rector, C., \& Warner, K. D. (2014). Community \& public health nursing:promoting the Public's Health. Philadelphia: Lippincott Williams \& Wilkins.

Anne shopie E. Darlington, et. all (2007). Coping Strategies as Determinants of Quality of Life in Stroke Patients: A Longitudinal Study. Cerebrovasc; 23-401-407.

Badan Pusat Statistik. (2011). Statistik penduduk lanjut usia Indonesia 2010. Jakarta:CV Petratama Persada

Cheng, et. all. (2012). The effectiveness of cargiver psycosocial interventions on the psycosocial wellbeing, physical health and quality of life of stroke family cargiver and their stroke survivor. JBI library of Systemic Review; JBI: 10000403

Chiung-man $\mathrm{Wu}$ (2009) Learning to be a family caregiver for severely debilated stroke survivor during the first year in Taiwan. ProQuest LLC. UMI 3390233

Clarke, Wilcockson, Gibb (2011) Reframing rwask management in dementia care through collaborative learning. Health and social care in Community, 23-32.

Dayapoglu, Mehtap Tan (2010). Quality of live in stroke patiens: Journal of Neurology. Nursing School. Sep 2010; DCI: 10.4103.

Edwards, B. and O'Connell, B. (2003). "Internal conswastency and validity of the Stroke Impact Scale 2.0 (SWAS 2.0) and SWAS-16 in an Australian sample." Quality of Life Research 12(8): 1127-1135

Elizabeth A. Jhonson.(2008) Factors Associated With Post -Stroke Depressive Symptoms And Quality of life. Indiana University, Proquest LLC. MI 48106-1346.

Ellen Towned, et. all. (2009). Feeling sad and useless': an investigation intopersonal 
acceptance of dwasability and its association with depression following stroke. Clinical rehabilitation 2010; 24: 556-564.

Ekawati Sutikno (2011). Hubungan antara Fungsi Keluarga dan Kualitas Hidup Lansia. Jurnal Kedokteran Indonesia, Vol. 2/NO. 1/Januari/2011.

Fransesco, Jose Egido (2009). Quality of Life after stroke: The importance of a Good Recovery: Journal Stroke Cerebrovasc Dwas; 27:204-214

Gunilla Gosman-Hedstrom, Lwasbeth Claesson,Chrwastian Blomstrand (2008), Consequences of severity at stroke onset for health-related quality of life (HRQL) and informal care: A 1-year follow-up in elderly stroke survivors. Archives of Gerontology and Geriatrics 47 79-91.

Jennifer, et. all. (2009). Cargiver Characterwastics Predict Stroke Quality of IIfe at 4 Months and 1 Year.Reaserch in nUrsing \& Health: 32, 592-605.

Joan S. Grant, et. all. (2006). Social support, social problem-solving abilities, and adjusment of family cargiver of stroke survivor. Arch phys rehabilitation vol 87.

Marieke Van Puymbroeck, Maude R. Rittman (2005) Quality-of-life predictors for caregivers at 1 and 6 months poststroke: Results of path analyses. Journal of Rehabilitation Research \& DevelopmentVolume 42, Number 6, Pages 747-760

Maurer, F. A., \& Smith, C. M. (2005). Community/public health nursing practice: health for families and populations. Philadelphia: Elsevier Saunders.

McCubin, H. McCubbin \& Thompson, A (1991) Family Assassment Inventories for Research and Practice, Madwason: University of Winconsin, Madwason.

Miller, C. A. (2012). Nursing for wellness in older adults: theory and practice. sixth edition. Philadelphia: J.B Lippincott Company.

Muslihati, I., Lisandy, Y., Kasanah, R., \& Winarko, H. (2018). Effect Of Education Media Video On Improve Stroke Prevention Behavior In Continued Age In Wiyurejo Pujon Malang. Journal Of Nursing Practice, 1(2), 12-17. https://doi.org/10.30994/jnp.v1i2.28

Pakaratee Chaiyawata, Kongkiat Kulkantrakornb (2012). Effectiveness of home rehabilitation program for waschemic stroke upon dwasability and quality of life: A randomized controlled trial. Clinical Neurology and Neurosurgery 114 866-870

Riskesdas (2007). Profil kesehatan indonesia. Jakarta

Riskesdas (2007). Profil kesehatan kalimantan Barat . Jakarta

Rosalyn J. Pawlak (2006) Reasons Persons with Stroke Seek Health Care Services After Dwascharge Home. Master of Science in Nursing. University of Ohio. (Tidak Dipublikasi)

Susan KY Chow (2007) Coping and caring: support for family caregivers of stroke survivors. Journal compilation Blackwell Publwashing Ltd. doi: 10.1111/j.13652702.2006.01711.x.

Townsend, M.C. (2009). Psychiatric mental health nursing.sixth edition : concepts of care in evidence-based practice. Philadephia. F.A. Davwas Company 
The Internet Stroke Center. 2011. Stroke statwastics. http://www.strokecenter.org/. diunduh tanggal 22 Februari 2014

UNFPA \& Help Age International. (2012). Ageing in the twenty-first century: a celebration and a challenge. New York

United States Cencus Beureu. (2012). US Department of commerce. www.cencus.gov. diakses tanggal 10 Februari 2013, pukul 10.15

Vicki Stemmons Mercer, et. all. Step Test Scores Are Related Measures of Activity and Participation in the First 6 Months After Stroke. Psysical therapy vol 89.

WHO (2004). WHO quality of life BREF. Geneva: World Health Organization 